\title{
PENGARUH BEBAN KERJA TERHADAP KINERJA PERAWAT DI INSTALASI RAWAT INAP RSUD LABUANG BAJI MAKASSAR
}

\section{EFFECT OF WORKLOAD ON PERFORMANCE OF NURSES IN INPATIENT OF GENERAL HOSPITAL LABUANG BAJI MAKASSAR}

\author{
Erlina ${ }^{1}$, Alwy Arifin ${ }^{2}$, Andi Ummu Salmah ${ }^{3}$ \\ ${ }^{1}$ Program Pascasarjana, Departmen Administrasi dan Kebijakan Kesehatan, Fakultas \\ Kesehatan Masyarakat, Universitas Hasanuddin \\ ${ }^{2}$ Departmen Administrasi dan Kebijakan Kesehatan, Fakultas Kesehatan Masyarakat, \\ Universitas Hasanuddin \\ ${ }^{3}$ Departmen Biostatistik/KKB, Fakultas Kesehatan Masyarakat, Universitas Hasanuddin
}

Alamat Korespondensi: Fakultas Kesehatan Masyarakat Universitas Hasanuddin, Makassar, 90242 HP:+6285299222907, Email: erlina_hb@yahoo.com

\begin{abstract}
Abstrak
Beban kerja merupakan sejumlah target pekerjaan atau hasil yang harus dicapai dalam suatu satuan waktu, dimana seluruh kegiatan atau aktivitas yang dilakukan oleh seorang perawat selama bertugas disuatu unit pelayanan keperawatan yang merujuk pada jumlah prosedur dan pemeriksaan kunjungan pada pasien. Tujuan penelitian ini adalah untuk mengetahui pengaruh beban kerja terhadap kinerja perawat. Jenis penelitian yang digunakan adalah Analitik observasional dengan pendekatan cross sectional study. Populasi dalam penelitian ini sebanyak 130 responden dengan teknik pengambilan sampel Exhaustive Sampling dimana semua jumlah populasi dijadikan sampel penelitian. Hasil penelitian ini, menujukkan bahwa Hasil uji statistik dengan menggunakan uji chi-square diperoleh nilai $p=0,011$, karena nilai $p$ value $<0,05$ maka ada pengaruh beban kerja direct care terhadap kinerja perawat. Hasil uji statistik dengan menggunakan uji chi-square diperoleh nilai $p=0,015$, karena nilai $p$ value $<$ 0,05 maka ada pengaruh beban kerja indirect care terhadap kinerja perawat. Diharapkan semua variabel beban kerja berpengaruh terhadap kinerja perawat perlu diperhatikan dan dijadikan tolak ukur dalam pengambilan kebijakan kedepannya di Institusi rumah sakit.
\end{abstract}

Kata kunci : Beban kerja, Kinerja perawat.

\begin{abstract}
Workload is the number of job targets or outcomes that must be achieved in a time unit, in which all activities or activities performed by a nurse during duty in a nursing service unit that refers to the number of procedures and examination of visits to the patient. The purpose of this study is to determine the effect of workload on the performance of nurses. The type of research used is observational analysis with cross sectional study approach. Population in this research as many as 130 respondents with sampling technique Exhaustive Sampling where all population amount used as sample research. The result of this study shows that the result of statistical test by using chi-square test is obtained p value $=0,011$, because $p$ value $<0,05$ hence there is influence of direct care workload to nurse performance. The result of statistical test by using chi-square test obtained $p$ value $=0,015$, because $p$ value $<0,05$ then there is influence of indirect care work load to nurse performance. It is expected that all workload variables affect the performance of nurses should be considered and used as a benchmark in future policy making in hospital institutions.
\end{abstract}

Keywords: Workload, Nurse Performance. 


\section{PENDAHULUAN}

Pelayanan keperawatan merupakan bentuk pelayanan profesional dari pelayanan kesehatan, didasarkan pada ilmu dan kiat keperawatan yang ditujukan kepada individu, keluarga, kelompok dan massyarakat baik secara sehat maupun sakit. Perawat dalam memberikan pelayanannya dilakukan secara konstan, terus-menerus dan menjadi konstribusi dalam menentukan kulaitas rumah sakit (Nursalam, 2011). Tenaga keperawatan mempunyai kontribusi besar dalam mencapai kinerja Puskesmas dan Rumah Sakit. Oleh karena itu, mutu tenaga perawat akan terus ditingkatkan profesionalismenya secara berkesinambungan (Kementerian Kesehatan, 2011).

Profesionalisme perawat dalam memberikan pelayanan keperawatan, dapat mempengaruhi hasil kinerja perawat. Bila kinerja perawat dalam pelayanan dasar maksimal, maka kualitas terhadap mutu pelayanan kesehatan menjadi lebih baik (Kasmir, 2016). Kinerja perawat dalam asuhan keperawatan dapat diartikan sebagai kepatuhan perawat dalam melaksanakan asuhan keperawatan, yang terdiri dari pengkajian, diagnosa, rencana tindakan, implementasi dan evaluasi (Manurung, 2011).

Penurunan kinerja berakibat pada rasa kepuasan pasien dan keluarga, dimana hal tersebut akan berdampak pada mutu pelayanan rumah sakit. Faktor yang mempengarugi terjadinya resiko penurunan kinerja salah satunya adalah beban kerja. Peningkatan beban kerja dapat terjadi, jika jumlah perawat tidak sesuai dengan tingkat kebutuhan perawatan pada pasien (Gilles 2009). Beban kerja adalah seluruh kegiatan atau aktifitas yang dilakukan oleh seorang perwat. Beban kerja ( workload) dapat diartikan sebagai patient day yang merujuk pada suatu prosedur pemeriksaan kunjungan (visite) pada pasien (Marques \& Huston, 2010).

Rumah Sakit Umum Daerah Labuang Baji merupakan rumah sakit tipe B - Berdasarkan pengambilan data awal di RSUD Labuang Baji Makassar tentang Bed Occupancy Rate (BOR) yang merupakan salah satu indikator untuk mengetahui tingkat pemanfaatan dan efisiensi pelayanan serta merupakan salah satu indikator untuk menilai kinerja di rumah sakit. Pada tahun 2014 nilai indikator efisiensi pemanfaatan tempat tidur mencapai 44.74\%, kemudian pada tahun 2015 nilai indikator efisiensi pemanfaatan tempat tidur meningkat yaitu $46.78 \%$, dan pada tahun 2016 nilai indikator efisiensi pemanfaatan tempat tidur mengalami penurunan drastis yaitu 29.18\%. Efesiensi pemanfaatan tempat tidur RSUD Labuang Baji belum memenuhi standar Depkes yakni $60 \%-85 \%$. Disamping itu, jumlah kunjungan pasien di Instalasi Rawat Inap RSUD Labuang Baji jumlahnya berfluktuasi atau tidak stabil dalam tiga tahun terakhir dimana jumlah kunjungan mengalami peningkatan dari 11.542 kunjungan di tahun 2014 menjadi 12.199 kunjungan ditahun 2015. Namun, ditahun 2016 mengalami penurunan yang cukup drastis yakni 7.419 kunjungan. Menurunnya angka kunjungan pasien di Instalasi Rawat Inap RSUD Labuang Baji menunjukkan bahwa pelayanan yang diberikan petugas kesehatan kurang baik dan belum maksimal (Profil RSUD Labuang Baji, 2016).

Berdasarkan penelitian yang dilakukan oleh Elisabeth (2015) di Irina CI RSUP Prof. Dr. R Kandou Manado, menunjukkan sebagian besar $(56,25 \%)$ perawat memilki beban kerja rendah. Hal ini disebabkan karena adanya keseimbangan antara jumlah perawat dengan jumlah pasien dan juga sebagian besar $(60 \%)$ pasien yang ada di Irina C1 tergolong dalam minimal care/self care yaitu pasien yang dapat melakukan sendiri kebersihan diri, mandi dan ganti pakaian, makan dan minum. Namun demikian, pasien perlu diawasi ketika melakukan ambulasi atau gerakan. Penelitian ini sejalan dengan penelitian yang dilakukan oleh Afandi (2013) di RSUD Saras Husada Purworejo yang menyatakan 53,9\% responden memilki beban kerja yang rendah.

Beban Kerja menjadi salah satu Faktor yang penting yang dapat dilihat dari 
Pemberi pelayanan kesehatan di Rumah sakit, dalam hal ini perawat yang menjadi Ujung tombak pemberi pelayanan di Organisasi kesehatan baik rumah sakit maupun lainnya sehingga beban kerja yang dirasakan harus dapat disertai dengan halhal yang mendukung kualitas dan kuantitas kerjanya dalam pemberian pelayanan yang baik dan sesuai Prosedur tetap yang dibutuhkan dan diharapkan.salah satunya bagi mereka yang bertugas di Instalasi rawat inap. Dengan kondisi dan latar belakang kerja dan tugas yang sewaktuwaktu berhadapan langsung dengan Pasien dengan berbagai macam jenis penyakit dan diagnosanya. Tujuan pnelitian ini adalah untuk menilai pengaruh beban kerja terhadap kinerja perawat di Instalasi Rawat Inap RSUD Labuang Baji Kota Makassar.

\section{BAHAN DAN METODE}

\section{Lokasi dan Desain Penelitian}

Penelitian ini dilakukan di RSUD Labuang Baji Makassar di Instalasi rawat inap. Jenis penelitian yang digunakan adalah observasional analitik dengan desain cross sectional study.

\section{Populasi dan Sampel}

Populasi dalam penelitian ini adalah seluruh perawat pelaksana yang ada di Instalasi Rawat Inap RSUD Labuang Baji Makassar tahun 2018 yang berjumlah 130 orang. Teknik pengambilan sampel adalah dengan menggunakan teknik exhaustive sampling berjumlah 130 orang.

\section{Teknik Pengumpulan Data}

Data diperoleh dari hasil pembagian kuesioner secara langsung kepada responden. Responden menjawab sendiri pertanyaan pada lembar kuesioner yang dibagikan yang berisi tentang identitas responden (jenis kelamin, umur, pendidikan terakhir, status keperawatan, dan lama kerja) dan item pertanyaan mengenai beban kerja terhadap kinerja perawat.

\section{Analisis data}

Analisis data dalam penelitian ini adalah analisis univariat, bivariat dan multivariat. Analisis univariat dilakukan untuk melihat karakteristik responden yang disajikan dengan tabel distribusi frekuensi.

Analisis bivariat dilakukan untuk mengetahui pengaruh masing-masing variabel dependen dan variabel independen dengan menggunakan uji Chi-Square. Analisis multivariat, dilakukan untuk mengetahui variabel yang paling berpengaruh terhadap kinerja perawat.

\section{HASIL}

\section{Karakteristik Responden}

Tabel 1 menunjukkan karakteristik responden berdasarkan jenis kelamin, usia, pendidikan terakhir, status kepegawaian dan gaji. Berdasarkan karakteristik jenis kelamin, sebagian besar responden adalah 5 responden $(52,1 \%)$ yang berjenis kelamin laki-laki dan 125 responden $(96,2 \%)$ responden yang berjenis kelamin perempuan. Berdasarkan umur terdapat 94 responden $(72,3 \%)$ yang memiliki rentang usia 20-39 tahun, dan 36 responden $(27,7 \%)$ dengan rentang usia $\geq 40$ tahun. Berdasarkan pendidikan terdapat 27 responden (20,8\%) dengan pendidikan DIII Keperawatan, 52 responden $(40,0 \%)$ responden dengan pendidikan $\mathrm{S} 1$ Keperawatan, sedangkan 51 responden $(39,2)$ dengan pendidikan Ners. Berdasarkan lama kerja terdapat terdapat 10 responden $(7,7 \%)$ dengan lama kerja 1-4 tahun, dan 120 responden $(92,3 \%)$ responden dengan lama kerja $\geq 5$ tahun. Dan berdasarkan status kepegawaian terdapat 90 responden $(72,6 \%)$ yang berstatus PNS dan 40 responden $(30,8 \%)$ yang berstatus Non-PNS. 
Tabel 1: Karakteristik Responden

\begin{tabular}{llcc}
\hline Karakteristik & & \multirow{2}{*}{ Kategori } & \multicolumn{2}{c}{ Frekuensi } \\
\cline { 3 - 4 } Responden & Laki-Laki & $\mathrm{N}$ & $\%$ \\
\hline \multirow{3}{*}{ Jenis Kelamin } & Perempuan & 5 & 3,8 \\
& Total & 125 & 96,2 \\
\multirow{4}{*}{ Umur } & 20-39 Tahun & 130 & 100 \\
& $\geq 40$ Tahun & 94 & 72,3 \\
& Total & 36 & 27,7 \\
\multirow{3}{*}{ Pendidikan Terakhir } & DIII Keperawatan & 130 & 100 \\
& S1 Keperawatan & 27 & 20,8 \\
& Ners & 52 & 40,0 \\
Status Kepegawaian & Total & 51 & 39,2 \\
& PNS & 130 & 100 \\
& Non PNS & 90 & 69,2 \\
Lama Kerja & Total & 40 & 30,8 \\
& $1-4$ tahun & 130 & 100 \\
& $\geq 5$ tahun & 10 & 7,7 \\
Sumy & Total & 120 & 92,3 \\
& & 130 & 100 \\
\hline
\end{tabular}

Sumber: DataPrimer, 2018

Tabel 2: Distribusi Responden Berdasarkan beban kerja direct care dan beban kerja indirect care di Instalasi Rawat Inap RSUD Labuang Baji Makassar Tahun 2018

\begin{tabular}{|c|c|c|}
\hline Variables & $\mathrm{N}$ & $\%$ \\
\hline \multicolumn{3}{|l|}{ Direct care } \\
\hline Cukup & 109 & 83,8 \\
\hline Kurang & 21 & 16,2 \\
\hline Total & 130 & 100 \\
\hline \multicolumn{3}{|l|}{ Indirect care } \\
\hline Cukup & 67 & 51,5 \\
\hline Kurang & 63 & 48,5 \\
\hline Total & 130 & 100 \\
\hline
\end{tabular}

Sumber: Data Primer, 2018

\section{Kegiatan langsung (Direct Care)}

Tabel 2 menunjukkan bahwa dari 130 responden terdapat 109 responden $(83,8 \%)$ yang beban kerja direct carenya cukup dan 21 responden (16,2\%) yang beban kerja direct carenya kurang, dan responden lebih banyak pada beban kerja direct cukup.

Tabel 3 menunjukkan terdapat 98 responden $(89,9 \%)$ yang memiliki kinerja baik, dan kinerja kurang sebanyak 11 responden (10,1\%). Sedangkan dari total 21 responden yang menyatakan beban kerja kurang, terdapat 14 responden (66,7\%) yang memilki kinerja baik dan 7 responden (33,3\%) yang memilki kinerja kurang. Hasil uji statistik dengan menggunakan uji chisquare diperoleh nilai $p=0,011$, karena nilai $p$ value $<0,05$ maka ada pengaruh beban kerja direct care terhadap kinerja perawat. 


\section{Kegiatan tidak langsung (Indirect Care)}

Table 2 menunjukkan terdapat 67 responden (51,5\%) yang beban kerja indirect carenya cukup dan 63 responden $(48,5 \%)$ yang beban kerja indirect carenya kurang, dan responden lebih banyak pada beban kerja indirect cukup.

Tabel 3 menunjukkan indirect care, dari total 67 responden yang menyatakan beban kerja indirect care cukup, terdapat 63 responden (94,0\%) yang memiliki kinerja baik, dan kinerja kurang sebanyak
4 responden (6,0\%). Sedangkan dari total 63 responden yang menyatakan beban kerja kurang, terdapat 49 responden $(77,8 \%)$ yang memilki kinerja baik dan 14 responden (22,2\%) yang memilki kinerja kurang. Hasil uji statistik dengan menggunakan uji chi-square diperoleh nilai $p=0,015$, karena nilai $p$ value $<0,05$ maka ada pengaruh beban kerja indirect care terhadap kinerja perawat.

Tabel 3: Analisis Bivariat Pengaruh Direct care dan Indirect Care Terhadap Kinerja Perawat di Instalasi Rawat Inap RSUD Labuang Baji Makassar Tahun 2018

\begin{tabular}{|c|c|c|c|c|c|c|c|}
\hline \multirow{3}{*}{ Variabel } & \multicolumn{4}{|c|}{ Kinerja Perawat } & \multirow{2}{*}{\multicolumn{2}{|c|}{ Total }} & \multirow{3}{*}{ Hasil Uji Statistik } \\
\hline & \multicolumn{2}{|c|}{ Baik } & \multicolumn{2}{|c|}{ Kurang } & & & \\
\hline & $\mathrm{N}$ & $\%$ & $\mathrm{n}$ & $\%$ & $\mathrm{~N}$ & $\%$ & \\
\hline \multicolumn{8}{|l|}{ Direct Care } \\
\hline Cukup & 98 & 89,9 & 11 & 10,1 & 109 & 100 & $p=0.011$ \\
\hline Kurang & 14 & 66,7 & 7 & 33,3 & 21 & 100 & \\
\hline \multicolumn{8}{|l|}{ Indirect Care } \\
\hline Cukup & 63 & 94,0 & 4 & 6,0 & 67 & 100 & $p=0.015$ \\
\hline Kurang & 49 & 77,8 & 14 & 22,2 & 63 & 100 & \\
\hline
\end{tabular}

Sumber: Data Primer, 2018.

Tabel 4: Hasil Analisis Multivariat dengan Regresi Logistik Pengaruh Variabel Beban Kerja Terhadap Kinerja Perawat di Instalasi Rawat Inap RSUD Labuang Baji Makassar Tahun 2018

\begin{tabular}{clcccccc}
\hline & Variabel & B & S.E & Wald & Df & Sig. & Exp (B) \\
\hline \multirow{2}{*}{ Step } & Direct care & 1,969 &, 676 & 8,491 & 1 &, 004 & 7,160 \\
$\mathbf{1}^{\mathbf{a}}$ & Indirect care & 1,647 &, 671 & 6,032 & 1 &, 014 & 5,193 \\
& Constant & $-9,640$ & 2,091 & 21,258 & 1 &, 000 &, 000 \\
\hline
\end{tabular}

Sumber: Data Primer, 2018.

\section{Analisis Multivariat}

Table 4 menunjukkan bahwa variabel yang memiliki $\mathrm{p}<0,05$ yaitu direct care $(p=0,004)$, indirect care $(p=0,014)$ yang berarti secara statistik semua variabel tersebut memiliki pengaruh secara bersama-sama terhadap kinerja perawat. Berdasarkan hasil tersebut, dapat dilihat bahwa model akhir persamaan regresi logistik untuk menentukan variabel beban kerja yang sangat berpengaruh terhadap kinerja perawat adalah dengan melihat nilai
$\operatorname{Exp}(B)$ (nilai estimasi oddsratio) atau nilai eksponen dari koefisien persamaan regresi yang terbentuk, yang paling tinggi ada pada variabel direct yaitu sebesar 7,160 kali dari variabel lain terhadap kinerja perawat di Instalasi Rawat Inap RSUD Labuang Baji Makassar, dengan nilai $\mathrm{p}=0,004$.

\section{PEMBAHASAN}

Hasil penelitian menunjukkan bahwa ada pengaruh beban kerja direct care terhadap kinerja perawat di instalasi rawat 
inap RSUD Labuang Baji Makassar ( $\mathrm{p}=$ 0,011). Hal ini dikarenakan banyaknya jumlah kegiatan yang harus dilakukan untuk memenuhi kebutuhan pasien. Dari hasil pengamatan dapat dilihat salah satu aktifitas yang membuat perawat dituntut untuk bekerja secara cepat agar semua pasien dapat dilayani.

Menurut Shah, et al dalam Febri (2015), tekanan atau beban kerja dapat menjadi positif, hal ini mengarah pada peningkatan kinerja. Adanya penerapan beban kerja membuat karyawan dituntut untuk mengeluarkan seluruh potensi yang dimiliki. Menurut perawat tekait tuntutan rumah sakit untuk mengerti diluar bidang keperawat seperti manajemen rumah sakit, asuransi dan kesapsiagaan dalam menagani pasien dalam keadaan apapun membuat perawat terus meningkatkan kemampuan yang dimiliki sehingga dapat meningkatkan kinerja pelayanan asuhan keperawatan. Hal ini sejalan dengan penelitian yang dilakukan Titok Sefridinata (2013) dengan hasil beban kerja berpengaruh positif dan signifikan tehadap kinerja perawat yang menunjukkan kondisi peningkatan beban kerja diikuti usaha yang kuat dari perawat untuk meningkatkan kinerja pelayanan.

$$
\text { Berdasarkan hasil penelitian }
$$

Supratman and Utami (2009) mengenai beban kerja untuk kegiatan langsung menunjukkan beban kerja berat sebesar $50 \%$ dan beban kerja ringan sebesar $18,8 \%$. Kegiatan yang menjadi beban kerja berat pada perawat sebagian besar adalah kegiatan langsung.

Hasil penelitian menunjukkan bahwa ada pengaruh beban kerja indirect care terhadap kinerja perawat di instalasi rawat inap RSUD Labuang Baji Makassar $(\mathrm{p}=0,015)$. Yang dimana kegiatan keperawatan tidak langsung meliputi merupakan kegiatan tidak langsung yaitu merapikan lingkungan klien, menyiapkan atau memeriksa alat dan obat emergensi, melakukan koordinasi/ konsultasi dengan tim kesehatan lainnya, mengadakan atau mengikuti pre dan post konferes, keperawatan/kegiatan ilmiah keperawatan dan medis, memberikan bimbingan dalam melakukan tindakan keperawatan, melakukan komunikasi tentang obat klien dengan pihak farmasi/apotik, mengirim/menerima berita klien melalui telepon dan membaca status klien (Kurniadi, 2013).

Berdasarkan penelitian yang dilakukan oleh Elisabet Manuho (2015), diperoleh hasil uji statistik dengan menguunakan chi square didalapatkan hasil yaitu $\alpha=0.035$ yang berarti dengan nilai $\alpha$ lebih besar dari niali $\alpha=0,05$ sehingga dapat disimpulkan bahwa $\mathrm{H}_{0}$ ditolak dan $\mathrm{H}_{\mathrm{a}}$ diterima dengan demikian dapat disimpulkan bahwa ada hubungan beban kerja dengan kinerja perawat.

Berdasarkan hasil penelitian Supratman dan Utami (2009), mengenai beban kerja kegiatan tidak langsung menunjukkan bahwa beban kerja berat sebesar 68,8\% dan beban kerja ringan sebesar $31,2 \%$. Pekerjaan tidak langsung perawat yang kebanyakan merupakan kegiatan hasil pengkajian, membuat rencana keperawatan, mendokumentasikan hasil/evaluasi tindakan dan kegitan yang secara tidak langsung berhubungan dengan pasien.

\section{KESIMPULAN DAN SARAN}

Dari hasil penelitian dapat disimpulkan bahwa ada pengaruh beban kerja kegiatan langsung (asuhan aktifitas keperawatan) dan kegiatan tidak langsung terhadap kinerja perawat di instalasi rawat inap di RSUD Labuang Baji Makassar tahun 2018. Sebagai saran dalam penelitian ini yaitu agar mempertahankan proporsi beban kerja yang sudah cukup baik serta meningkatkan agar proporsi beban kerja lebih baik lagi, karena hasil dari penelitian membuktikan bahwa beban kerja berpengaruh positif terhadap kinerja dan Kinerja perawat akan tetap berada pada level tertinggi yang dapat berdampak positif terhadap perkembangan rumah sakit kedepan.

\section{DAFTAR PUSTAKA}

Afandi. (2013). Analisis pendekatan Balance Scorecard Sebagai Suatu Sistem Pengukuran Kinerja (studi 
kasus pada Rumah Sakit Ibnu Sina).

Universitas Muslim Indonesia.

Lembaga Penelitian Universitas

Hasaniddin Makassar.

Elisabeth, M. Warow, H. (2015). Hubungan

Beban Kerja Dengan Kinerja

Perawat Dalam Pemberian Asuhan

Keperawatan Di Instalasi Rawat

Inap C 1 RSUP PROF. Dr. D.

Kandou Manado. Ejournal Keperawatan (e-Kep) 3.

Febri Furqon. (2015). Pengaruh kepuasan dan beban kerja terhadap kinerja karyawan pada PT. Merapi Agung Lestari. Universitas Negeri Yogyakarta.

Gillies D.A. (2009). Nursing Management a Syestem Approach. Third edition : WB Saunders. Philadelpia.

Hasmi. (2016). Metode Penelitian Kesehatan, Jayapura, In Media.

Kasmir. (2016). Manajemen Sumber Daya Manusia ( Teori Dan Praktik). Jakarta: Raja Grafindo Persada.

Kementerian Kesehatan RI . (2011). Perawat Mendominasi Tenaga Kesehatan.

Kurniadi, A. (2013). Manajemen Keperawatan Dan Prospektifnya : Teori Dan Aplikasi. Jakarta : Fakultas Kedokteran UI.

Marquis Dan Huston. (2010). Kepemimpinan dan manajemen Keperawatan.: Teori dan Aplikasi ed 4. Alih bahasa: Widyawati dan Handayani. Jakarta : EGC.

Manurung, Santa. (2011). Keperawatan Profesialisme, Jakarta: Tim.

Nursalam. (2011). Konsep dan Penerapan Metodologi Penelitian Ilmu Keperawatan. Jakarta, Salemba Medika.

Supratman. Utami, (2009).

Pendokumentasian Asuhan Keperawatan Ditinjau Dari Beban Kerja Perawat. Berita Ilmu Keperawatan ISSN 1979-2697, Vol. 2 No. 1, Maret 2009:7-12. FIK, UMS.

Profil Rsud Labuang Baji. (2016). Profil

Rumah Sakit Umum Daerah Labuang Baji Makassar. 